\title{
A COMPUTERIZED SUBSTRUCTURE CONSTRUCTION PLANNING APPROACH
}

\author{
Kuo-Liang Lin, and Kuei-Yen Chen
}

\author{
I-Shou University, Kaohsiung, Taiwan
}

\begin{abstract}
This paper presents a computerized planning approach to optimize substructure construction sequence for medium to high rise buildings in restricted urban areas. Common substructure construction alternatives include traditional excavation and strutting method, top/down method, and "go over next slab" method. Since different alternative may result in different construction cost and duration, the best alternative would be the one that yields the least construction cost and meanwhile has a favorable construction schedule meeting project requirement. Important planning factors include soil conditions, number of floors and floor height of the substructure and superstructure, diaphragm wall strength, mining excavation efficiency and possible outlets, formwork use, and miscellaneous secondary works associated with each method. Through intensive interviews and literature survey, a systematic planning process with computerized components is developed. With this planning approach, planners can effectively evaluate more substructure construction alternatives and so forth to determine an optimal substructure construction method. As growing concerns of cost and scheduling impacts on urban development projects arise, the approach described in this paper can serves as a valuable development towards construction automation.
\end{abstract}

Keywords: computerized planning, construction method, substructure construction, excavation, top/down construction.

\section{INTRODUCTION}

For medium to high rise building development in restricted urban areas, substructure construction is usually the key to project's overall construction cost and duration. For urban area development, diaphragm wall is usually the obvious choice for retaining purpose due to the congestion nature (Law 1995). After the diaphragm wall is place, excavation follows. Straight excavation and strutting is the most common used method for building the basement floors. Superstructure cannot started until the substructure, including the excavation down to the lowest slab as well as all basement floors, is completed. Excavation and strutting is straightforward and considered very reliable. For this traditional excavation and strutting method, project duration is the total of the time for building basement floors and that for building superstructure. In early 80 s, an innovative method called "top/down method" which allows overlapping of the underground and superstructure construction process was attempted (Tatum and Bauer 1989). Using $1^{\text {st }}$ floor slab or other underground slab as strutting, top/down methods allow superstructure and underground floors to be proceeded simultaneously. The main purpose of using top/down construction methods is to reduce overall project duration (Paek and Jong 1996). Utilization of top/down method, however, may sometimes result in higher construction cost due to the decreased productivity in excavation and basement building and some additional secondary works such as waterproofing and non-shrunk grouting for slab-column joint for the basement slabs. Originally top/down method is to excavate the basement floors once at a time (called "pure top/down" in this paper), which results in miscellaneous secondary works at every basement floors. These miscellaneous secondary works are tedious, costly activities and can sometimes be very time consuming. To further shorten underground construction duration and minimize miscellaneous secondary works, a modified method "go over next slab" is developed (Lee et al.1999). Unlike original top/down method to excavate one basement floor at a time, the "go over next slab" allows excavation works for two consecutive floors to be done simultaneously. To withstand the increased lateral earth pressure due to increased unsupported excavation depth, some permanent or temporary reinforcement to the diaphragm wall is usually required. This additional reinforcement means additional cost items to the project, while on the other hand miscellaneous secondary works can be reduced due to the skipped slab. Top/down method and go-over-next slab method can be conbined to generate many different modified methods for specific project needs. Table 1 is a detailed comparison of these aforementioned methods (Chen 1993). 
Table 1. Comparison of Substructure Construction Methods

\begin{tabular}{|c|c|c|c|}
\hline & Excavation and Strutting & Top/Down Method & Go-Over-Next-Step \\
\hline $\begin{array}{l}\text { Working } \\
\text { Platform }\end{array}$ & $\begin{array}{l}\text { Working platform required during } \\
\text { substructure construction }\end{array}$ & Use completed slab as platform & $\begin{array}{l}\text { Use completed slab as } \\
\text { platform }\end{array}$ \\
\hline Retaining & $\begin{array}{l}\text { Require temporary strutting; usually } \\
\text { with larger defection; can cause } \\
\text { problems to adjacent buildings }\end{array}$ & $\begin{array}{l}\text { Use completed slab as strutting, } \\
\text { smaller deflection }\end{array}$ & $\begin{array}{l}\text { Use completed slab as } \\
\text { strutting; Increased } \\
\text { unstrutted depth may } \\
\text { require minor } \\
\text { reinforcement to reduce } \\
\text { deflection }\end{array}$ \\
\hline $\begin{array}{l}\text { Excavation } \\
\text { Depth }\end{array}$ & $\begin{array}{l}\text { Suitable for all depths but strutting for } \\
\text { deep excavation can be laborious }\end{array}$ & Better for deep excavation & $\begin{array}{l}\text { Better for deep excavation } \\
\text { with sound soil conditions }\end{array}$ \\
\hline $\begin{array}{l}\text { Work } \\
\text { Sequence }\end{array}$ & $\begin{array}{l}\text { Sequentially from substructure to } \\
\text { superstructure }\end{array}$ & $\begin{array}{l}\text { Substructure and superstructure } \\
\text { proceed simultaneously; } \\
\text { excavate one story at a time }\end{array}$ & $\begin{array}{l}\text { Substructure and } \\
\text { superstructure proceed } \\
\text { simultaneously; excavation } \\
\text { can have various } \\
\text { combination }\end{array}$ \\
\hline $\begin{array}{l}\text { Work } \\
\text { Duration }\end{array}$ & $\begin{array}{l}\text { Long duration since no overlapping is } \\
\text { possible }\end{array}$ & $\begin{array}{l}\text { Although mining efficiency is } \\
\text { decreased, overlapping } \\
\text { superstructure and substructure } \\
\text { saves a lot of time }\end{array}$ & $\begin{array}{l}\text { Substructure duration can } \\
\text { be further compressed. }\end{array}$ \\
\hline Cost & $\begin{array}{l}\text { Cost for strutting roars as depth } \\
\text { increase; Additional cost for platform } \\
\text { and strutting }\end{array}$ & $\begin{array}{l}\text { Additional cost for top/down } \\
\text { columns, temporary PC, } \\
\text { miscellaneous secondary works, } \\
\text { temporary ventilation and } \\
\text { lighting, but minus strutting and } \\
\text { platform }\end{array}$ & $\begin{array}{l}\text { Same as top/down but can } \\
\text { have reduced miscellaneous } \\
\text { secondary works and } \\
\text { possibly additional } \\
\text { temporary strutting or } \\
\text { reinforcement cost }\end{array}$ \\
\hline
\end{tabular}

\section{PLANNING FACTORS}

Global construction business has become very competitive. Contractors always have to provide their clients more construction alternatives to meet specific project requirements. To devise an appropriate substructure construction is not an easy task. Planners not only have to evaluate project characteristics against feasibility of each method, but also to assess complicated trade-off between money and time in different methods. To determine if a top/down method or a modified method is feasible or more appropriate for a specific project, the following planning factors have to be considered: soil conditions, basement floor height, number of floors of the substructure and superstructure, diaphragm wall strength, possible reinforcement scheme available, mining excavation efficiency and possible outlets, use of formworks, miscellaneous secondary works associated with different construction methods, and starting slab for the construction. The following describes major impacts of these factors on the planning decision:

1. Soil conditions: Soil conditions of the job site determine the feasibility of using the "go over next slab" method. Better soil conditions can effectively reduce the need of reinforcement to withstand increased unsupported excavation depth.
2. Basement floor height : Basement floor height affects the unsupported excavation depth during the mining process.

3. Number of floors in the substructure and superstructure: Number of floors in the substructure and superstructure determines whether the "down" (substructure) or "top" (superstructure) construction duration is going to be the critical path to overall project duration.

4. Diaphragm wall strength: Safety factor of the diaphragm wall strength affects the extent of the reinforcement required if a modified excavation method is to be used.

5. Available reinforcement: Possible reinforcement includes increased diaphragm wall thickness and/or length, and temporary strutting to the diaphragm wall. The reinforcement mechanism can affect the underground construction duration as well as the cost. A very large basement floor height can make infeasible any reinforcement scheme.

6. Mining excavation efficiency and possible outlets: Mining excavation efficiency and possible mining outlets affects the substructure construction duration, which is to be evaluated against overall project duration when a modified method is to be used.

7. Use of formworks: Number of forworks used in "down" (substructure3) and "top" (superstructure) construction affects their respective concrete 
works efficiency, which eventually determine the "down" and "top" durations.

8. Miscellaneous secondary works: Miscellaneous secondary works required in top/down method increased overall construction cost, and time to perform these works can affect the substructure construction duration.

9. Starting slab: Starting slab of the top/down method represents the division of two separated work phases of "top" part and "down" part. Planners can shift the starting slab to balance the top and down duration if necessary.

Figure 1 is an influence diagram showing the relationship of these factors and project objectives.

\section{PLANNING PROCEDURE}

By analyzing the planning factors, several feasible alternatives can be identified for the project. For each alternative, planners should develop detailed construction sequence, design reliable strutting or diaphragm reinforcing mechanism, and estimate the construction cost and duration. This is a timing trialand-error process with great complexity, which requires profound expert judgement. Through intensive interviews and literature survey, a systematic approach is developed to facilitate the planning. This approach adopts a step-by-step planning process allowing thorough examination of planning factors and evaluation of project constraints in a interactive way. The approach includes the following steps:

(1) Enumeration: to list all possible substructure construction alternatives with different sequences based on basement floors. Since the basement slab is to be used as lateral strutting during excavation, number of basement floors controls the combinations of excavation. Based on general geotechnical conditions in Taiwan urban

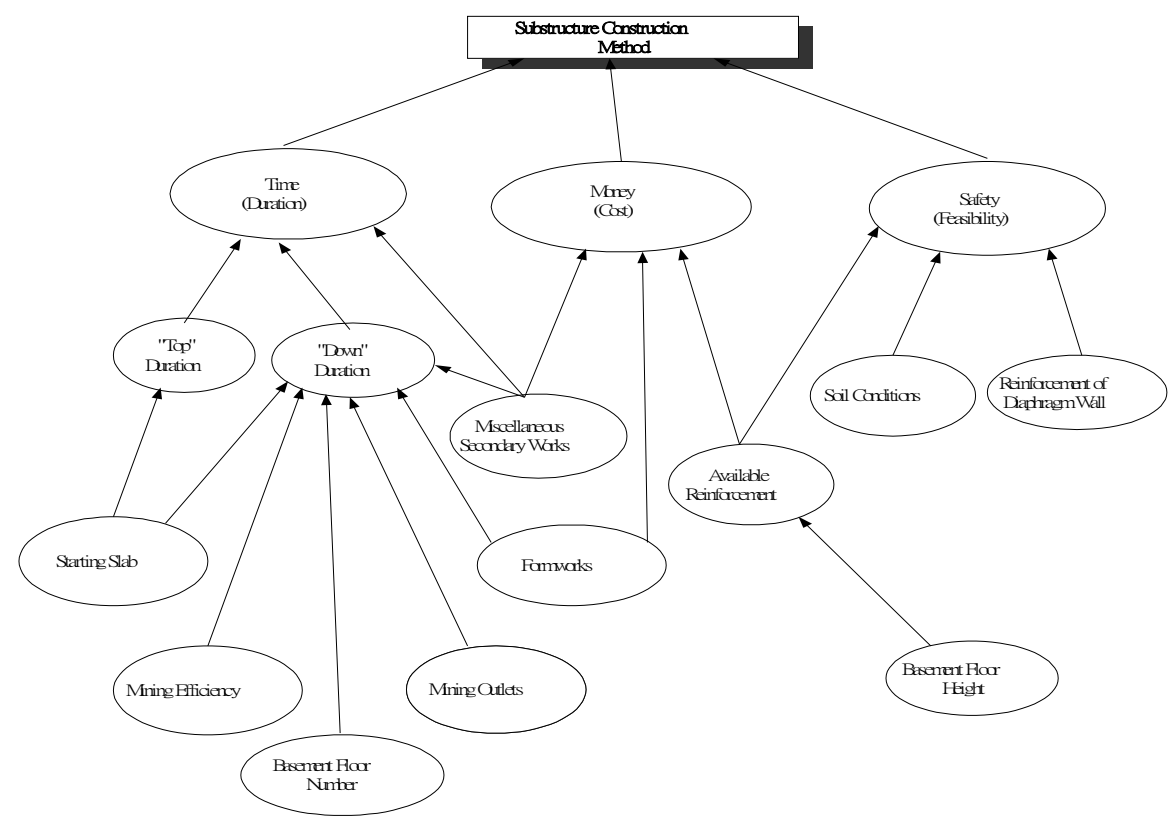

176_MD4.doc- 3 -

Figure 1 Influence Diagram for Planning Factors 
area, go-over-one slab excavation is usually the largest depth each excavation can go with none or reasonably minimum additional strutting or

Table 2 Possible Basement Excavation Alternatives

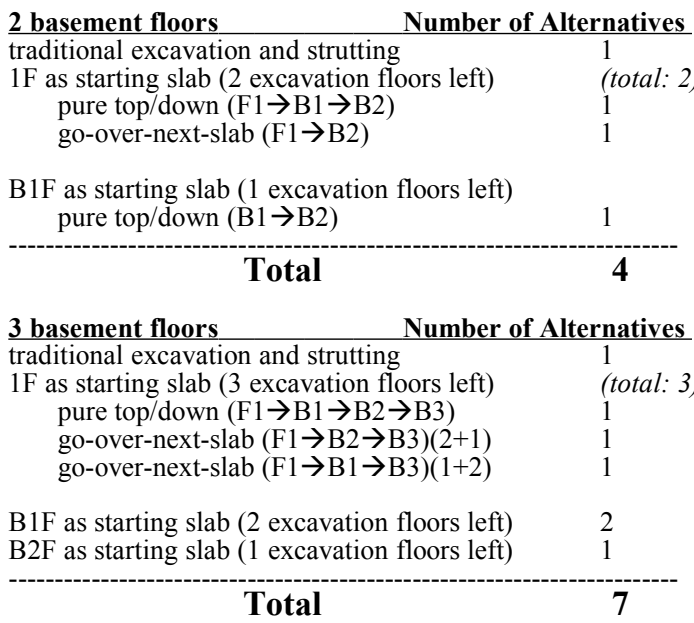

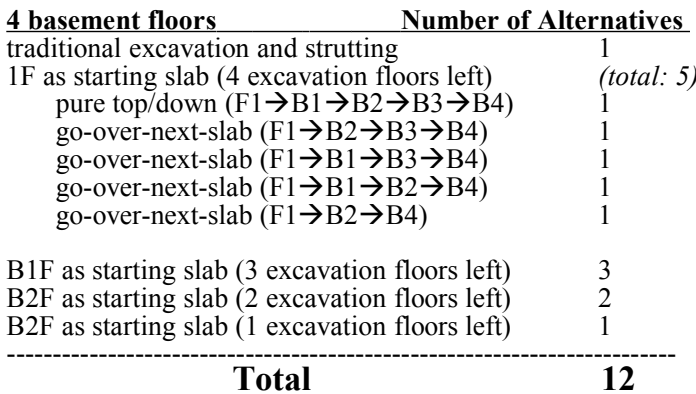

5 basement floors Number of Alternatives traditional excavation and strutting $1 \mathrm{~F}$ as starting slab ( 5 excavation floors left) pure top/down $(1+1+1+1+1)$ go-over-next-slab $(2+1+1+1)$ go-over-next-slab $(2+1+1+1)$
go-over-next-slab $(1+2+1+1)$ go-over-next-slab $(1+1+2+1)$ go-over-next-slab $(1+1+1+2)$ go-over-next-slab $(2+2+1)$ go-over-next-slab $(2+1+2)$ go-over-next-slab $(1+2+2)$

$\mathrm{B} 1 \mathrm{~F}$ as starting slab (4 excavation floors left) $\mathrm{B} 2 \mathrm{~F}$ as starting slab ( 3 excavation floors left) $\mathrm{B} 3 \mathrm{~F}$ as starting slab (2 excavation floors left) B4 as starting floor (1 excavation)

\section{Total}

21

6 basement floors Number of Alternatives traditional excavation and strutting $1 \mathrm{~F}$ as starting slab (6 excavation floors left) pure top/down $(1+1+1+1+1+1)$ go-over-next-slab $(2+1+1+1+1)$ go-over-next-slab $(1+2+1+1+1)$ go-over-next-slab $(1+1+2+1+1)$ go-over-next-slab $(1+1+1+2+1)$ go-over-next-slab $(1+1+1+1+2)$ go-over-next-slab $(2+2+1+1)$ go-over-next-slab $(2+1+2+1)$ go-over-next-slab $(2+1+1+2)$ go-over-next-slab $(1+2+2+1)$ go-over-next-slab $(1+2+1+2)$ go-over-next-slab $(1+1+2+2)$ go-over-next-slab $(2+2+2)$

$\mathrm{B} 1 \mathrm{~F}$ as starting slab (5 excavation floors left) $\mathrm{B} 2 \mathrm{~F}$ as starting slab (4 excavation floors left) $\mathrm{B} 3 \mathrm{~F}$ as starting slab (3 excavation floors left) B4F as starting slab (2 excavation floors left) B5F as starting slab (2 excavation floors left) reinforcement on the diaphragm wall. In very rare situation, go-over-two-slab would be possible, which is not discussed in this paper. For example, when developing underground construction method for a building with 2 basement floors, planners have a choice between traditional excavation and strutting method and the top/down method. If top/down method is to be used, either $1 \mathrm{~F}$ or $\mathrm{B} 1 \mathrm{~F}$ can be chosen as the starting slab. Using $1 \mathrm{~F}$ as the starting slab, the excavation from $1 \mathrm{~F}$ to $\mathrm{B} 2$ again has two different alternatives: to excavate one floor at a time (pure top/down: F1 $\rightarrow$ B1 $\rightarrow$ B2) and to go over B1 slab to B2 directly (go-over-next-slab: F1 $\rightarrow$ B2); while only pure top/down can be used when using B1 as the starting slab since only one story is left for the excavation. In summary, there is a total of 4 different construction sequences to choose. Table 2 lists all the possible basement excavation alternatives for different floor numbers (from 2 to 6). As shown, number of alternatives grows rapidly as number of basement floor increases. Some alternative may be very similar to others. However, due to possible floor height variation and different soil conditions at different depths, cost/time impacts of similar alternatives can vary. Technical feasibility of each alternative is to be further evaluated later on.

(2) Elimination: to remove infeasible alternatives considering retaining possibility. Some alternative can be practically infeasible because of retaining possibility, especially for those goover-next-slab ones with additional strutting requirement. Very soft soil conditionals prevent a reasonably economic and timesaving strutting system from being possible. The alternative should be eliminated when the cost and time for strutting installation exceeds a certain extent. A simple commercial application RIDO is used for this evaluating purpose. As a maximum additional strutting capacity is determined, each alternative should go through a RIDO evaluating procedure as shown in Figure 2 to test its feasibility. Only feasible alternatives remain for further evaluation.

Figure 2. RIDO Evaluating Procedure 
(3) Nomination: to identify nominated alternatives in various duration categories. Preliminary cost and schedule for each alternative will be estimated at this stage. Several alternatives can have similar construction duration. The objective is to identify the least expensive alternative in various duration categories. Construction duration described here is the overall project duration which includes duration required for the superstructure (top part) on and the substructure (down part). Superstructure working rate is usually described as the number of days per story completed, which can be precisely estimated and controlled by experienced contractors. Substructure schedule, on the other hand, depends on many project constraints, such as mining outlets on the job site, available resources such as workforce and formworks, and most importantly, the construction method and sequence chosen for the project. Mining efficient of tradition excavation and strutting method is usually better than that of top/down method, but its superstructure cannot start until the underground is completed. Top/down method can effectively overlap the "top" and "down" construction activities. Starting slab of a top/down method represents the division of two separated working phases (top and down). When the starting slab is built, work can be done simultaneous above and under this slab. The remaining works above and under the slab thus delineate the top and down duration respectively. Different construction sequences also result in different combinations of cost items, which resemble the overall construction cost. Scheduling templates for different sequences (excavation and strutting, pure top/down method, and go-over-next-slab method) are provided for fast duration estimate. These schedule templates, developed using Microsoft Project 98, allow planners to enter project constraints, and scheduling parameters such as working rates and other available resources, and then automatically calculate the overall project duration as well as the "top" and "down" duration,. Computerized estimate sheets, based on Microsoft Excel, for typical underground methods are also provided to facilitate estimating process. With this estimate sheets, planners can effortlessly calculate the preliminary construction cost for each alternative. As preliminary cost and duration for each alternative estimated, planners therefore select several more representable ones for future evaluation; that is, among alternatives with similar construction duration, retrieve the nominated one with least construction cost as the final alternative.

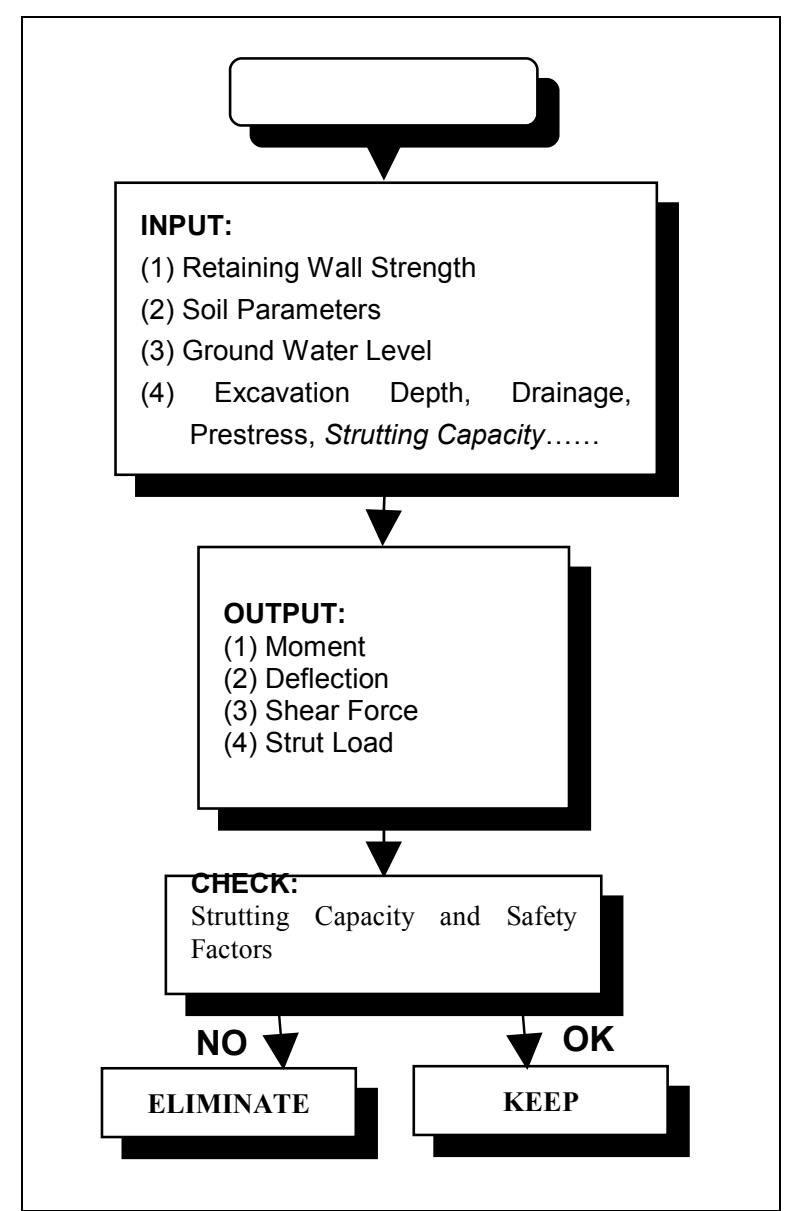

(4) Comparison and Finalization: to evaluate the cost and scheduling trade-offs of final alternatives against project requirements. Alternative adopting the traditional excavation and strutting method is usually used as a baseline, which usually has the longer construction schedule and the lower cost. Benefit-Cost ratio and expenditure per construction day saved for other alternatives can be calculated and presented to the client for final decision.

\section{CASE STUDY}

This planning method has been tested in a multipurpose office building project located in Nan-Tzi industrial district in Kaohsiung, Taiwan ( $\mathrm{Da}$ Cin 1999). The main part of this project is a 9-story RC building with a 5 -story basement. Total jobsite area is $10,768 \mathrm{~m}^{2}$. Excavation depth is $17.65 \mathrm{~m}$. The designed retaining system includes a $100 \mathrm{~cm}$ thick, $32 \mathrm{~m}$ deep diaphragm wall surrounding the jobsite. The owner is a high-tech IC company, who is intended to use this building as their extended headquarter in Southern Taiwan. Part of the building will room the company's top labratory facility. As high-tech industry becomes extremely competitive, the timing of opening this new office is the owner's top concern. Since the building has 5 basement 
floors, there are 21 possible alternatives. After preliminary elimination and selection, 4 finalists are nominated for final selection:

(A) traditional excavation and strutting

(B) pure top/down (using 1F as starting slab)

(C) modified top/down (using B1 as starting slab)

(D) go-over-next slab $(1 \mathrm{~F} \rightarrow \mathrm{B} 2 \rightarrow \mathrm{B} 4 \rightarrow \mathrm{B} 5)(2+2+1)$

Figure 4 is a schedule comparison of these alternatives and Table 3 is their schedule and cost trade-off. Using (A) excavation and strutting method as the baseline. Cost per day saved for each alternative is also calculated. Alternative(C) and Alternative(D) have shorter project duration and a relatively low cost per day saved so that final decision comes down to these two obvious candidates. Since Alternative(D) has the shortest duration and the difference of cost per day saved from Alternative(C) is negligible to a project this scale, Alternative(D) becomes the owner's final selection.

Table 3. Schedule and Cost Trade-off

\begin{tabular}{|c|c|c|c|}
\hline Alternative & Cost (NT\$) & Duration & \$ / day \\
\hline (A) & $\$ 1,090,000,000$ & $381 \mathrm{~d}$ & -- \\
\hline (B) & $\$ 1,120,000,000$ & $338 \mathrm{~d}$ & $\$ 697,674$ \\
\hline (C) & $\$ 1,115,000,000$ & $302 \mathrm{~d}$ & $\$ 316,456$ \\
\hline (D) & $\$ 1,123,000,000$ & $294 \mathrm{~d}$ & $\$ 379,310$ \\
\hline
\end{tabular}

Top/down method and its kinds have tremendous advantages over traditional excavation and strutting method in terms of scheduling aspect. As technology of top/down method getting matured and other innovative substructure construction method being developed, the importance of devising an appropriate substructure construction procedure to suit a specific project arises and the decision making becomes even more complicated. The method described in this paper provides a practical way for planners to contemplate and analyze all related planning elements towards an optimal solution in a step-bystep manner. This method also adopts computerized modules, including RIDO evaluating procedure, Excel estimate sheets, and Microsoft Project scheduling templates, to facilitate the entire planning process. The research team is now working on incorporating AI modules integrating expert knowledge to current development to further automate the planning process.

\section{REFERENCES}

[1] C. B. Tatum, M. F. Baure, and A. W. Meade, "Process of innovation up/down Construction at Rows Wharf", Journal of Construction

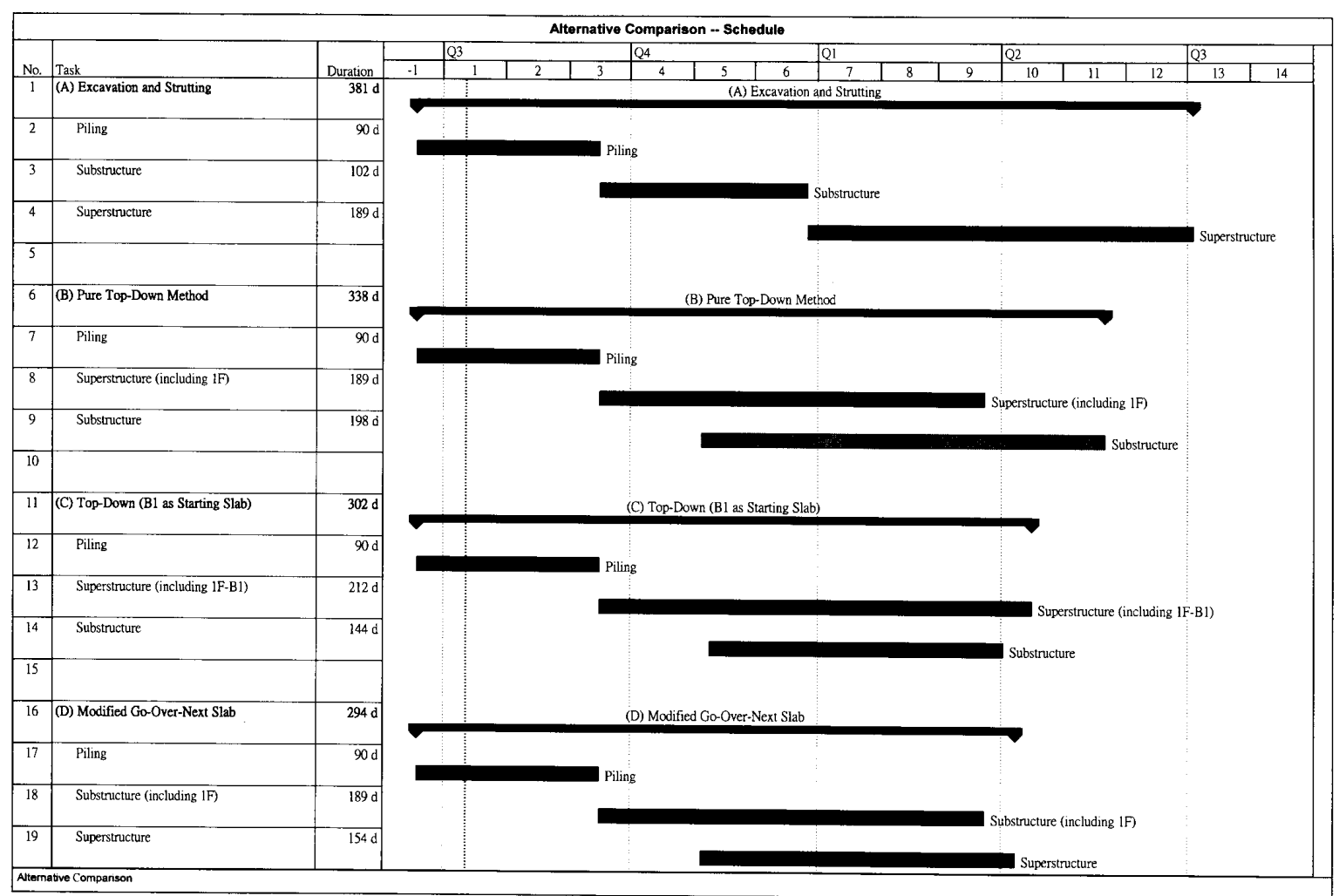

Figure 4. Bar Chart Comparison of Alternatives

Engineering and Management, ASCE, 115(2), p.p. $179 \sim 195.1989$.

\section{CONCLUSIONS}


[2] J. H. Paek, and J. H. Ock . "Innovative Building Construction Techniques" Journal of Construction Engineering and Management, ASCE, 122(2), pp. 179-195. 1996.

[3] H. S. Lee, J. Y. Lee, and J. S. Lee. "Nonshored Formwork System for Top-Down Construction" Journal of Construction Engineering and Management, ASCE, 125(6), pp. 392-399. 1999.

[4] Y. Y. Chen. Planning and Control for Top/Down Construction. Master's Thesis, National Taiwan Institute of Technology. 1993.

[5] H. Y. Law. Building Construction for Highrises. pp. 130-159. Jen's Bookstore, Taipei, Taiwan. 1995.

[6] Da Cin Construction Co. Ltd.. Construction Proposal for Hwa-Tai Kaohsiung Office Building. Unpublished Document. 1999. 